\title{
O PERFIL DOS PROFESSORES LEITORES DAS SÉRIES INICIAIS E A PRÁTICA DE LEITURA EM SALA DE AULA
}

\author{
Profile of readers-professors of the initial series \\ and the reading practice in classroom
}

\author{
Tristana Nascimento Barros ${ }^{(1)}$, Erissandra Gomes ${ }^{(2)}$
}

\begin{abstract}
RESUMO
Objetivo: investigar os hábitos e o comportamento dos professores de $1^{\underline{a}}$ a $4^{\mathrm{a}}$ série do ensino fundamental perante a leitura e a prática de leitura em sala de aula. Métodos: estudo observacional, transversal, com a participação de 30 professores de $1^{\underline{a}}$ a $4^{\underline{a}}$ séries, do ensino fundamental, de escolas públicas. Através de um questionário com 15 questões do tipo aberta e fechada, foram colhidas informações sobre os hábitos e atitudes dos professores frente ao aprendizado da leitura. Resultados: dos 30 professores estudados, houve diferença estatisticamente significativa entre os comportamentos $(p<0,001)$, sendo que o comportamento pouco favorável foi o mais prevalente entre os professores. Conclusão: a grande maioria dos professores não desenvolveu uma relação afetiva com a leitura na infância e não tem o hábito de leitura, tão necessário para formar pequenos leitores em bons-leitores.
\end{abstract}

DESCRITORES: Comunicação; Aprendizagem; Educação

\section{INTRODUÇÃO}

O trabalho fonoaudiológico na área educacional visa identificar e prevenir as alterações da comunicação oral e escrita, mas, especialmente, criar condições adequadas e eficazes, para possibilitar a otimização do desenvolvimento infantil, pois, as capacidades comunicativas de fala, audição, leitura e escrita, podem ser sempre melhoradas e facilitar a aprendizagem escolar ${ }^{1}$. Assim, a escola constitui-se em um dos campos de possíveis e efetivas ações preventivas relacionadas à saúde fonoaudiológica e, sob esse aspecto o trabalho do fonoaudiólogo favorece para que a escola se torne um lugar saudável e propício ao desenvolvimento das habilidades lingüísticas: o falar, ouvir, ler e escrever, em especial a habilidade de ler que interessa na pesquisa ${ }^{1}$.

(1) Fonoaudióloga; Prefeitura de Salto do Jacuí - RS; Especialização em Linguagem pelo CEFAC - Saúde e Educação; Pós-Graduada em Psicopedagogia Institucional pela Universidade Comunitária Regional de Chapecó - SC.

(2) Fonoaudióloga; Docente do Curso de Fonoaudiologia do Centro Universitário Metodista IPA; Mestre em Ciências Médicas: Pediatria pela Universidade Federal do Rio Grande do Sul.
Considerando-se que, o processo de aprender a ler e a escrever acontece, essencialmente, por duas vias, uma via envolve a construção das relações fonema/grafema, ou seja, corresponder letras com sons (codificação) e fonemas com grafemas (decodificação), aliadas ao aspecto motor, à prática de escrever da esquerda para a direita, de cima para baixo, a habilidade de agarrar o lápis, entre outros. A outra via consiste em usar esse conhecimento nas práticas sociais, é aprender a ler e escrever com o próprio uso. Conseqüentemente, as duas vias são ações simultâneas e interdependentes, porém diferentes, em termos de processos de conhecimentos e de produtos, ainda, denominadas processo da alfabetização e do letramento ${ }^{1,2}$.

Toda a criança precisa aprender a usar a codificação e decodificação, conhecer as correspondências entre grafema e fonema, apropriar-se do sistema de escrita, adquirir o domínio do sistema ortográfico e ter o hábito e o prazer de ler e de escrever diversos tipos de textos, em diferentes contextos ou situações. Contudo, ensinar a ler, não significa ensinar as letras ${ }^{1-3}$.

Para um adequado desempenho lingüístico ao longo da vida escolar e cotidiana é fundamental promover o desenvolvimento de habilidades da leitura e da escrita nas crianças pequenas, mesmo que a 
criança não tenha aprendido a ler ou escrever, através de situações em que a língua oral ou escrita é objeto da atenção, como na leitura de livros, onde o adulto lê histórias, a criança escuta rimas, vincula conceitos, faz inferência, percebe a sintaxe complexa e as estruturas narrativas dos textos. Também, as competências pré-alfabéticas (conhecimento da escrita e consciência fonológica). Avaliando a qualidade das interações criança-adulto, uma vez que desperta o interesse e a motivação pela leitura e pela escrita ${ }^{3}$.

A leitura é uma habilidade lingüística fundamental para o desenvolvimento da comunicação oral e escrita e, conseqüentemente, para o desenvolvimento infantil ${ }^{4-6}$ Começa bem antes do aprendizado das letras, quando alguém lê e a criança escuta por prazer. É o contar de história que desperta o gosto pela leitura e desenvolve bons-leitores ${ }^{5,7}$. Além disso, a atitude positiva do professor frente à leitura mostra-se como um fator fundamental na aprendizagem e desenvolvimento do hábito de leitura, pois, incentiva e contribui para a prática de leitura entre os alunos, sendo o exemplo o maior incentivador da leitura ${ }^{8-10}$.

Com base no exposto, o objetivo deste estudo foi investigar os hábitos e o comportamento dos professores de $1^{\underline{a}}$ a $4^{\underline{a}}$ série do ensino fundamental diante da leitura e a prática de ler em sala de aula.

\section{MÉTODOS}

Realizou-se um estudo observacional e transversal com professores de $1^{\underline{a}}$ a $4^{\underline{a}}$ séries do ensino fundamental, de seis escolas públicas: quatro escolas municipais e duas escolas estaduais, do Município de Salto do Jacuí, Rio Grande do Sul. A coleta dos dados foi realizada por meio de um questionário por escrito (Figura 1), com 15 questões: quatro do tipo aberta e 11 fechada, baseado em outras publicações ${ }^{6-10}$. Este instrumento buscou informações sobre o comportamento, as atitudes e preferências dos professores frente à leitura, entre outras.

Foram analisados todos os questionários devolvidos (30) e respondidos pelos professores, seguido do termo de consentimento para a coleta dos dados. Não foi considerado o tempo de atuação e à formação dos professores.

Para uma melhor apreciação as respostas das quatro questões abertas foram agrupadas de acordo com os termos de maior freqüência de ocorrência utilizada pelos professores e classificadas segundo alguns autores $4,5,8-10$.

Para determinar níveis que permitissem assinalar o perfil de professores leitores e com base nas pesquisas ${ }^{8,9}$, foram pontuadas as respostas de oito das 11 questões fechadas que fazem parte do questionário respondido pelos professores. As outras três questões fechadas não foram pontuadas porque alguns professores assinalaram mais de uma resposta, de modo que o número de respostas obtidas foi superior ao número de professores entrevistados. As oito questões fechadas que tiveram as suas respostas pontuadas estão relacionadas abaixo:

- Como foi a sua experiência pessoal, em relação ao ato de leitura, desde a sua infância até os cursos de formação?

"Uma atividade prazerosa e motivante" (3 pontos); "Uma obrigação acadêmica" (2 pontos); "Uma atividade negativa: chata e difícil" (1 ponto); "Não lembra" (0 ponto).

- Você considera que seu contato com livros de histórias na infância foi:

"Ótimo" (3 pontos); "Bom" (2 pontos); "Pouco" (1 ponto) e "nenhum" (0 pontos).

- Quando criança os seus pais liam para você? "Sim" (2 pontos); "Às vezes" (1 pontos); "Não" ou "não lembra" (0 ponto).

- Como você classifica o seu interesse pela leitura atualmente: "Ótimo" (3 pontos); "Bom" (2 pontos), "Regular" (1 ponto) e "Pouco" ou "nenhum" (0 ponto)

- Você costuma ler para ter prazer? "Sim" (2 pontos); "Às vezes" (1 ponto); "Não" ou "não sabe" (0 ponto).

- Como professor você realiza leitura de histórias infantis na sala de aula? "Sim" (3 pontos); "Só na biblioteca" ( 2 pontos); "Como atividade de casa" (1 ponto) e "Não" (0 ponto).

- Com que freqüência você realiza a leitura de histórias na sala de aula?

"Todos os dias" ou "Quase todos os dias" (2 pontos); "Às vezes" (1 ponto) e "Nunca" (0 ponto).

- Você utiliza qual abordagem de leitura em sala de aula?

"Orientada para o desempenho" (3 pontos); "Coconstrutivista" (2 pontos); "Didático-interacional" (1 ponto) e nenhuma ou não soube referir (0 ponto).

De acordo com a pontuação obtida nas 8 questões fechadas, os professores pesquisados foram inseridos em grupos de leitores. A divisão dos grupos foi baseada nos estudos ${ }^{8,9}$.

Grupo 1 - comportamento e atitudes frente ao ato de ler altamente favorável: de 20 a 21 pontos;

Grupo 2 - comportamento e atitudes frente ao ato de ler favorável: de 18 a 19 pontos;

Grupo 3 - comportamento e atitudes frente ao ato de ler pouco favorável: até 17 pontos;

Primeiramente, foi realizado contato com a Secretaria Municipal de Educação do Município 


\section{QUESTIONÁRIO}

\section{Identificação:}

Série que leciona:

Idade:

Sexo: ( ) F ( ) M

Formação: ( ) Técnico Magistério ( ) Curso Superior de férias ( ) Curso Superior

Tempo de trabalho no ensino fundamental:

( ) Escola Municipal

( ) Escola Estadual

1. Para você, o que é ler?

2. O aprendizado da leitura é uma responsabilidade de quem:

3. Como foi a sua experiência pessoal, em relação ao seu "período de aprender a ler", desde a sua infância até os cursos de formação?

( ) Uma atividade negativa: chata e cansativa.

( ) Uma atividade prazerosa e motivante.

( ) Uma obrigação acadêmica.

( ) Não lembra.

4. Você considera que o seu contato com livros de histórias na infância foi: ( )Pouco

( )Bom

( )Ótimo

( )Nenhum

5. Quando criança os seus pais liam para você? ( ) Sim ( )Não ( )Às vezes ( )Não lembra.

6. Como você classifica o seu interesse pela leitura, atualmente: ( )Ótimo ( )Bom

( )Regular ( )Pouco

Por quê?

7. O que você gosta de ler? ( ) Jornais

( ) Livros técnicos (da profissão)

( ) Revistas em geral.

( ) Mensagens e textos da internet.

( ) Livros diversos: romance, auto-ajuda, "best-seller", literário.

8. O que você compra para ler? ( ) Jornais ( ) Revistas ( ) Livros ( ) Não compra.

9. Você costuma ler para ter prazer? ( ) Sim ( ) Não ( ) Às vezes ( ) Não sabe referir.

10. Para você o hábito de leitura exige? ( ) Disposição e interesse pessoal.

( ) Condições financeiras para comprar livros.

( ) Competências específicas.

( ) Não sabe referir.

11. Por que é importante aprender a ler?

12. O que significa ser um bom-leitor?

13. Como professor você realiza leitura de histórias infantis na sala de aula?
( ) Sim
( ) Não
( ) Só na biblioteca
( ) Como atividade de casa.

14. Se sim, informe com que freqüência você realiza a leitura de histórias na sala de aula?
( ) Todos os dias
( ) Quase todos os dias
( ) Às vezes
( ) Nunca

15. Você utiliza qual abordagem de leitura em sala de aula?

( ) Co-construtivista: durante a leitura de histórias o professor complementa as passagens do texto, tanto espontaneamente como em resposta às perguntas das crianças.

( ) Didático-interacional: o professor assume o papel de liderança, é ele, por exemplo, quem faz as perguntas, às quais são em torno dos fatos ocorridos no texto.

( ) Orientada para o desempenho: durante a leitura, o professor encoraja as crianças a fazer previsões sobre o que vai acontecer na história, a estabelecer ligações entre os acontecimentos do texto com suas experiências pessoais, além de acrescentar informações importantes para compreensão da história.

\section{Figura 1 - Questionário aplicado aos professores}


para apresentar o projeto e solicitar a sua autorização. Depois, foi realizado o contato com os diretores das escolas e com os respectivos professores participantes que assinaram o Termo de Consentimento Livre e Esclarecido autorizando a coleta e utilização dos dados.

A pesquisa foi aprovada pelo o Comitê de Ética em Pesquisa do CEFAC - Saúde e Educação, sob número 152/06.

As variáveis quantitativas foram descritas através de média e desvio padrão, e as categóricas através de freqüências absolutas e relativas. Para comparar os grupos em relação à idade e ao tempo de trabalho no ensino fundamental foi aplicada a técnica de Análise de Variância (ANOVA) one-way. Para avaliar as associações entre as variáveis categóricas, o teste qui-quadrado de associação foi utilizado. Para comparar os grupos entre si, o teste quiquadrado de ajustamento foi aplicado. O nível de significância adotado foi de $5 \%$ e as análises foram realizadas no programa SPSS (Statistical Package for the Social Sciences) versão 13.0.

\section{RESULTADOS}

Do total de 42 professores de $1^{\text {a }}$ a $4^{\text {a }}$ séries do ensino fundamental, 30 professores devolveram os questionários. O tempo de profissão variou entre 2 e 29 anos, com média de 14,3 anos. Dois professores não informaram o tempo de trabalho no ensino fundamental. A caracterização da amostra está apresentada na Tabela 1.

A Figura 2 apresenta a distribuição dos professores quanto ao comportamento e atitude frente ao ato de ler. Houve diferença estatisticamente significativa entre os comportamentos $(p<0,001)$, sendo que o comportamento pouco favorável foi o mais prevalente entre eles.

A associação entre as características dos professores com o comportamento e atitude frente ao ato ler está na Tabela 2. Não houve associação estatisticamente significativa com nenhuma variável sócio-demográfica nem com as variáveis relacionadas à profissão, talvez pelo pequeno número de professores com o comportamento altamente favorável ao ato de ler $(n=1 ; 3,3 \%)$.

A Tabela 3 apresenta a associação entre as questões referentes ao comportamento e atitude frente ao ato ler com o grupo. Houve associação estatisticamente significativa com a questão "Quando criança os seus pais liam para você?" ( $p=0,021)$, sendo que o grupo 3 (pouco favorável) apresentou a maior proporção de respostas negativas. Também houve associação significante do grupo com a questão "Como você classifica o seu interesse pela leitura atualmente" $(p=0,006)$, sendo que o grupo 2
Tabela 1 - Caracterização da amostra

\begin{tabular}{|c|c|}
\hline Características & $\mathrm{n}=\mathbf{3 0}$ \\
\hline Idade (anos) - Média \pm DP & $37,6 \pm 6,93$ \\
\hline \multicolumn{2}{|l|}{ Sexo - n(\%) } \\
\hline Masculino & $02(6,7)$ \\
\hline Feminino & $28(93,3)$ \\
\hline \multicolumn{2}{|l|}{ Série que leciona* - n(\%) } \\
\hline $1^{\mathrm{a}}$ & $9(30,0)$ \\
\hline $2^{\mathrm{a}}$ & $11(36,7)$ \\
\hline $3^{\mathrm{a}}$ & $10(33,3)$ \\
\hline $4^{\mathrm{a}}$ & $9(30,0)$ \\
\hline Não informaram & $2(6,7)$ \\
\hline \multicolumn{2}{|l|}{ Formação - n(\%) } \\
\hline Técnico Magistério & $4(13,3)$ \\
\hline Curso Superior de férias & $13(43,3)$ \\
\hline Curso Superior & $10(33,3)$ \\
\hline Não informaram & $3(10,0)$ \\
\hline $\begin{array}{l}\text { Tempo de trabalho no ensino } \\
\text { fundamental (anos) - Média } \pm \text { DP }\end{array}$ & $14,3 \pm 7,60$ \\
\hline \multicolumn{2}{|l|}{ Escola - n(\%) } \\
\hline Municipal & $16(53,3)$ \\
\hline Estadual & $6(20,0)$ \\
\hline Ambas & $8(26,7)$ \\
\hline
\end{tabular}

${ }^{*}$ Questão de múltipla resposta, visto que alguns professores lecionam em várias séries.

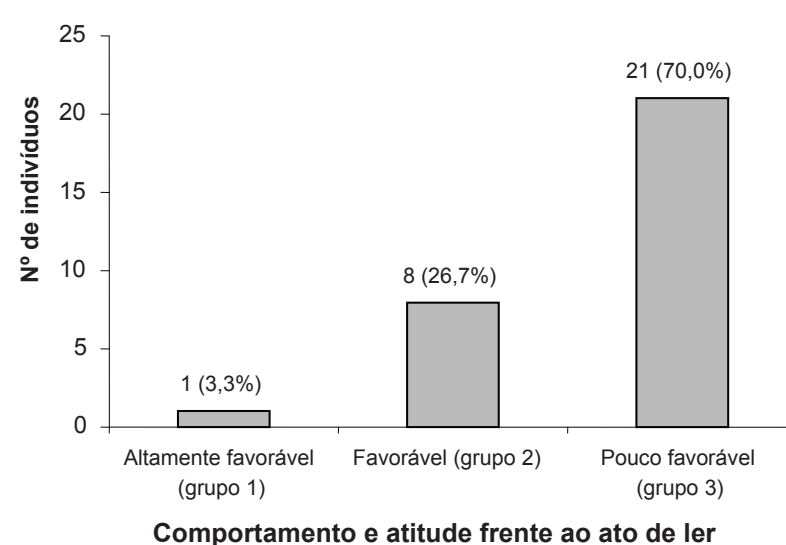

Figura 2 - Distribuição dos professores quanto ao comportamento e atitude frente ao ato de ler

(favorável) teve uma maior proporção de respostas na categoria "ótimo" e o grupo 3 (pouco favorável) estava mais associado à categoria "bom". Houve associação também entre os grupos com a questão de o hábito de leitura exigir competências específicas $(p<0,001)$, onde somente o grupo 1 (altamente favorável) considerou esse item. Porém, esse grupo possui apenas um professor, fazendo com que esta associação seja interpretada com cautela. 
Tabela 2 - Relação entre as características da amostra e o grupo

\begin{tabular}{|c|c|c|c|c|}
\hline Características & $\begin{array}{c}\text { Grupo } 1 \\
(n=1)\end{array}$ & $\begin{array}{c}\text { Grupo } 2 \\
(n=8)\end{array}$ & $\begin{array}{c}\text { Grupo } 3 \\
(n=21)\end{array}$ & $\mathbf{p}$ \\
\hline Idade (anos) - Média \pm DP & $27 \pm 0,0$ & $40,4 \pm 8,73$ & $37,1 \pm 5,82$ & $0,155^{\star \star}$ \\
\hline \multicolumn{5}{|l|}{ Sexo $-n(\%)$} \\
\hline Masculino & $0(0,0)$ & $1(12,5)$ & $1(4,8)$ & \multirow[t]{2}{*}{$0,729^{\star * *}$} \\
\hline Feminino & $1(100,0)$ & $7(87,5)$ & $20(95,2)$ & \\
\hline \multicolumn{5}{|l|}{ Série que leciona ${ }^{*}-\mathrm{n}(\%)$} \\
\hline $1^{\underline{a}}$ & $0(0,0)$ & $2(25,0)$ & $7(33,3)$ & $0,665^{\star * *}$ \\
\hline $2^{\mathrm{a}}$ & $0(0,0)$ & $3(37,5)$ & $8(38,1)$ & $0,976^{* * *}$ \\
\hline $3^{\text {a }}$ & $0(0,0)$ & $1(12,5)$ & $9(42,9)$ & $0,124^{\star * *}$ \\
\hline $4^{\mathrm{a}}$ & $0(0,0)$ & $4(50,0)$ & $5(23,8)$ & $0,173^{\star \star \star}$ \\
\hline Não informaram & $1(100,0)$ & $1(12,5)$ & $0(0,0)$ & - \\
\hline \multicolumn{5}{|l|}{ Formação - n(\%) } \\
\hline Técnico Magistério & $0(0,0)$ & $2(25,0)$ & $2(9,5)$ & \multirow[t]{4}{*}{$0,789^{* * *}$} \\
\hline Curso Superior de férias & $1(100,0)$ & $2(25,0)$ & $10(47,6)$ & \\
\hline Curso Superior & $0(0,0)$ & $3(37,5)$ & $7(33,3)$ & \\
\hline Não informaram & $0(0,0)$ & $1(12,5)$ & $2(9,5)$ & \\
\hline $\begin{array}{l}\text { Tempo de trabalho no ensino } \\
\text { fundamental (anos) - Média } \pm \text { DP }\end{array}$ & $6,0 \pm 0,0$ & $15,6 \pm 10,3$ & $14,2 \pm 6,4$ & $0,505^{\star *}$ \\
\hline \multicolumn{5}{|l|}{ Escola - $n(\%)$} \\
\hline Municipal & $0(0,0)$ & $4(50,0)$ & $12(57,1)$ & \multirow[t]{3}{*}{$0,557^{* * *}$} \\
\hline Estadual & $0(0,0)$ & $2(25,0)$ & $4(19,0)$ & \\
\hline Ambas & $1(100,0)$ & $2(25,0)$ & $5(23,8)$ & \\
\hline
\end{tabular}

* Questão de múltipla resposta, visto que alguns professores lecionam em várias séries.

** Valor obtido pela Análise de Variância (ANOVA) one-way.

*** Valor obtido pelo teste qui-quadrado de Pearson.

\section{DISCUSSÃO}

A leitura é um ato complexo, que abrange processos perceptuais, cognitivos, lingüísticos, comunicativos, sociais e emocionais. É muito importante considerar as condições afetivas, interesse e motivação em relação ao ato de ler, para que se possa garantir prazer e gosto pela leitura no dia-a-dia da vida. Qualquer alteração em um destes aspectos pode causar prejuízos no processo de desenvolvimento e aprendizagem ${ }^{5-10}$.

A partir das informações obtidas nos questionamentos aplicados aos professores, pode-se constatar que dos 30 professores de $1^{\underline{a}}$ a $4^{\underline{a}}$ série do ensino fundamental, somente 1 apresentou comportamento altamente favorável para a leitura, determinado por uma experiência pessoal positiva com relação à leitura, desde a infância, através do contato com livros infantis e hábito dos pais de contarem histórias. Sabe-se que, é essencial desenvolver a motivação e gosto pela leitura, desde muito cedo, antes do aprendizado formal, através do contato direto com livros infantis e diversos tipos de textos (poesias, parlendas, adivinhas, contos, gibis, entre outros), a relação afetiva com a leitura se estabelece na infância, portanto, para constituir-se um bom leitor a prática de leitura precisa ser desenvolvida em casa e na escola ${ }^{5-9}$.

Vinte e um professores apresentaram comportamento pouco favorável para a leitura, assinalado por uma experiência pessoal não positiva com a leitura, quase a metade dos professores pesquisados consideraram que o ato de ler foi uma imposição escolar ou uma atividade chata. Confirmando, o que se sabe em diversos estudos ${ }^{8-10}$, que a prática de leitura por obrigação na escola, como tarefa escolar, não forma leitores permanentes e críticos, mas, sim leitores ocasionais e passageiros, que tem a sensação de que ler é uma atividade cansativa e desinteressante. A grande maioria dos professores afirmou que teve pouco ou nenhum contato com livros de histórias na infância e que seus pais nunca realizaram leitura de histórias infantis para eles quando criança. Houve associação estatisticamente significativa com esta questão $(p=0,021)$, sendo que o grupo 3 (pouco favorável) apresentou 
Tabela 3 - Representação dos professores leitores e a prática de leitura nas séries iniciais

\begin{tabular}{|c|c|c|c|c|}
\hline Questionamentos & $\begin{array}{c}\text { Grupo1 } \\
(n=1)\end{array}$ & $\begin{array}{c}\text { Grupo2 } \\
(\mathrm{n}=8)\end{array}$ & $\begin{array}{c}\text { Grupo3 } \\
(n=21)\end{array}$ & $\mathbf{p}^{* *}$ \\
\hline \multicolumn{5}{|l|}{$\begin{array}{l}\text { Como foi a sua experiência pessoal, em } \\
\text { relação ao ato de ler, desde a sua infância } \\
\text { até os cursos de formação? }\end{array}$} \\
\hline Uma atividade prazerosa e motivante. & $1(100,0)$ & $8(100,0)$ & $7(33,3)$ & 0,081 \\
\hline Uma atividade negativa: chata e cansativa & - & - & $5(23,8)$ & \\
\hline Uma obrigação acadêmica. & - & - & $7(33,3)$ & \\
\hline Não lembra. & - & - & $2(9,5)$ & \\
\hline \multicolumn{5}{|l|}{ Quando criança os seus pais liam para } \\
\hline Sim & - & $2(25,0)$ & $1(4,8)$ & \\
\hline Às vezes & - & $1(12,5)$ & $17(81,0)$ & \\
\hline Não & - & $1(12,5)$ & $1(4,8)$ & \\
\hline \multicolumn{5}{|l|}{ Não lembra } \\
\hline \multicolumn{5}{|l|}{$\begin{array}{l}\text { Você considera que seu contato com livros } \\
\text { de histórias na infância foi: }\end{array}$} \\
\hline Ótimo & $1(100,0)$ & $3(37,5)$ & $3(14,3)$ & 0,511 \\
\hline Bom & - & $1(12,5)$ & $3(14,3)$ & \\
\hline Pouco & - & $3(37,5)$ & $10(47,6)$ & \\
\hline Nenhum & - & $1(12,5)$ & $5(23,8)$ & \\
\hline \multicolumn{5}{|l|}{$\begin{array}{l}\text { O aprendizado da leitura é uma } \\
\text { responsabilidade de quem: }\end{array}$} \\
\hline Pais, professores e alunos. & $1(100,0)$ & $3(37,5)$ & $6(28,6)$ & 0,668 \\
\hline Pais e professores. & - & $4(50,0)$ & $6(28,6)$ & \\
\hline Professores e alunos. & - & $1(12,5)$ & $2(9,5)$ & \\
\hline Só do aluno e/ou da família. & - & - & $6(28,6)$ & \\
\hline Sem resposta. & - & - & $1(4,8)$ & \\
\hline \multicolumn{5}{|l|}{ Por que é importante aprender a ler? } \\
\hline Fim lingüístico. & - & $1(12,5)$ & $3(14,3)$ & 0,901 \\
\hline Fim profissional. & - & $1(12,5)$ & $2(9,5)$ & \\
\hline Fim cultural. & $1(100,0)$ & $4(50,0)$ & $6(28,6)$ & \\
\hline Fim social. & - & $2(25,0)$ & $9(42,9)$ & \\
\hline Sem resposta. & - & - & $1(4,8)$ & \\
\hline \multicolumn{5}{|l|}{ Você costuma ler para ter prazer? } \\
\hline Sim & $1(100,0)$ & $7(87,5)$ & $8(38,1)$ & 0,158 \\
\hline Ás vezes & - & $1(12,5)$ & $12(57,1)$ & \\
\hline Não & - & - & - & \\
\hline Não sabe referir & - & - & $1(4,8)$ & \\
\hline
\end{tabular}

*Alguns professores assinalaram mais de uma resposta, de modo que o número de respostas obtidas foi superior ao número de professores entrevistados.

** valor obtido pelo teste qui-quadrado de Pearson. 
Tabela 3 (continuação)

\section{Questionamentos}

O que você compra para ler? *

Jornais

Revistas

Livros

Não compra

\section{Para você o hábito de leitura exige? *}

Disposição e interesse pessoal.

Condições financeiras para comprar livros.

Competências específicas.

\section{Como você classifica o seu interesse pela leitura atualmente:}

Ótimo

Bom

Regular ou Pouco

Não respondeu.

Para você, o que é ler?

Visão acadêmica ou lingüística.

Visão cultural.

Visão interacional.

Visão afetiva.

Sem resposta.

\section{0 que significa ser um bom leitor?}

Ter hábito constante de leitura, gostar e sentir prazer.

Ler freqüentemente vários tipos de textos.

Entender e interpretar o que leu.

Sem resposta.

$\begin{array}{cccc}\begin{array}{c}\text { Grupo1 } \\ \text { n (1) }\end{array} & \begin{array}{c}\text { Grupo2 } \\ \text { n (8) }\end{array} & \begin{array}{c}\text { Grupo3 } \\ \text { n (21) }\end{array} & \mathbf{p}^{* *} \\ & & & \\ - & 4(50,0) & 11(52,4) & 0,592 \\ - & 4(50,0) & 11(52,4) & 0,592 \\ 1(100,0) & 7(87,5) & 9(42,9) & 0,064 \\ - & - & 4(19,0) & 0,372\end{array}$

$\begin{array}{llll}1(100,0) & 8(100,0) & 20(95,2) & 0,801 \\ - & 1(12,5) & 3(14,3) & 0,916 \\ 1(100,0) & - & - & <0,001\end{array}$

$\begin{array}{llll}1(100,0) & 7(87,5) & 2(9,5) & 0,006 \\ - & 1(12,5) & 9(42,9) & \\ - & - & 7(33,3) & \\ - & - & 3(14,3) & \end{array}$

$\begin{array}{llll}- & 3(37,5) & 10(47,6) & 0,695 \\ 1(100,0) & 2(25,0) & 7(33,3) & \\ - & 1(12,5) & 3(14,3) & \\ - & 1(12,5) & - & \\ - & 1(12,5) & 1(4,8) & \\ & & & \\ & & & \\ - & 2(25,0) & 3(14,3) & 0,502 \\ - & 3(37,5) & 9(42,9) & \\ - & 2(25,0) & 8(38,1) & \\ & 1(12,5) & 1(4,8) & \end{array}$

Com que freqüência você realiza a leitura de histórias na sala de aula?
Todos os dias.

Quase todos os dias.

Às vezes

Nunca

$\begin{array}{llll}- & 3(37,5) & - & 0,086 \\ 1(100,0) & 2(25,0) & 9(42,9) & \\ - & 3(37,5) & 10(47,6) & \\ - & - & 2(9,5) & \end{array}$

\section{Você utiliza qual abordagem de leitura em} sala de aula?

Orientada para o desempenho.

Co-construtivista.

Didático-interacional.

Não responderam.

\begin{tabular}{llll}
$1(100,0)$ & $7(87,5)$ & $8(38,1)$ & 0,314 \\
- & $1(12,5)$ & $5(23,8)$ & \\
- & - & $6(28,6)$ & \\
- & - & $2(9,5)$ & \\
\hline
\end{tabular}

*Alguns professores assinalaram mais de uma resposta, de modo que o número de respostas obtidas foi superior ao número de professores entrevistados.

${ }^{* *}$ valor obtido pelo teste qui-quadrado de Pearson. 
a maior proporção de respostas negativas. Isto revela uma carência de material para leitura, em casa, que satisfaça aos interesses das crianças, como já foram apontadas nas pesquisas ${ }^{8-10}$, e evidência que, poucos pais têm por rotina realizar leituras para seus filhos, atitudes estas consideradas como de incentivo à formação de crianças e adolescentes em bons leitores ${ }^{5-7}$. Verifica-se uma relação afetiva não favorável em relação à leitura e uma formação deficiente dos professores e, consequentemente, a manutenção deste comportamento de "não-leitura", característico não só dos professores, mas de vários grupos sociais do nosso país ${ }^{8-10}$. O que se observou na pesquisa é que, a maioria dos professores apresenta uma relação meramente técnica ${ }^{10}$ e mecânica com a leitura, comprovando que, a relação-afetiva com a leitura não foi desenvolvida. Logo, como o professor pode comprometer-se em formar bons leitores, sendo o exemplo o grande incentivador do hábito de ler, o professor precisa gostar de ler.

$\mathrm{Na}$ questão que investigou o aprendizado da leitura é uma responsabilidade de quem. Chama a atenção que 7 professores excluíram-se dessa responsabilidade. Considerando que, o professor é o profissional habilitado e responsável para formar, mediar e orientar o aluno a construir o conhecimento, transformando-o em aprendizagem. Neste sentido, o professor é o grande mediador do aprendizado da leitura e responsável pela formação de pequenos leitores em bons leitores, capazes de fazer uso real da leitura no dia-a-dia da vida. Porém, o professor não é o responsável único pelo aprendizado da leitura ${ }^{7-10}$. O adulto em geral (sejam pais, professores ou terapeutas) tem a responsabilidade de ler diversos textos para a criança, de maneira lúdica, mostrando-lhe o sentido e a importância do aprendizado da leitura para o dia-a-dia da vida. Compete aos pais, também, dar início ao processo de aprendizado da leitura, motivando seus filhos a ler, por meio de exemplos positivos frente à leitura, através da leitura em voz alta de histórias infantis, de forma prazerosa, e dando livros de presente quando possível ${ }^{6-10}$. Estudo ${ }^{11}$ revelou que, as experiências de leitura compartilhada, desde bem cedo, antes da idade escolar, proporcionam um desempenho importante em todas as tarefas acadêmicas futuras. Relatou que leitores não capazes tiveram significativamente menos experiências de leitura compartilhada com seus pais antes do aprendizado formal do que os leitores capazes. Percebe-se que, nem sempre a família tem condições financeiras e culturais de desempenhar a tarefa de promover a prática da leitura ${ }^{8-10}$ em casa. Portanto, ainda, cabe ao professor orientar e incentivar esses pais a promoverem situações favoráveis de leitura em casa, revelando o valor das histórias infantis antes de dormir e a lembrança agradável das primeiras leituras para o futuro aprendizado da leitura. Além, da sua importância para o desenvolvimento da linguagem oral, da atenção, da imaginação, da memória, do vocabulário e desenvolvimento infantil como um todo, inclusive como função terapêutica, já que, ajuda na pacificação das emoções, incorporação de valores sociais, desenvolvimento do caráter e para o desempenho escolar. Estes achados foram corroborados por diversos estudos ${ }^{6-12}$. Outros estudos ${ }^{7-10}$, também, relacionam que mesmo os pais com boas condições econômicas não exercem o papel de incentivadores da leitura, pois, desconhecem sobre a necessidade da leitura desde bem cedo.

Quando questionados por que é importante aprender a ler, 22 professores descreveram um fim cultural ou social. Avaliando a importância do aprendizado da leitura como elemento que, possibilita desenvolver o conhecimento, ter acesso a informações, formar o espírito, ampliar idéias, questionar e pensar sobre as coisas do mundo, como forma de atividade social, capaz de formar cidadãos conscientes e competentes, comprometidos com as transformações sociais ${ }^{2,4,5,8,10}$. Entretanto, quase sempre, muitos professores trabalham com textos recursivos, cópias e exercícios dirigidos, sem a preocupação de desenvolverem atividades de uso efetivo da leitura, a fim de torná-la significativa ${ }^{5,8}$. É indiscutível, então, o fim cultural e social do aprendizado da leitura como comprovaram a maioria dos professores do estudo, pois, as pessoas lêem para resolver problemas, para anotar alguma coisa, para informar-se, para aprofundar conhecimentos, para ter prazer (fruição) e até para saber que não se sabe tudo ${ }^{5}$, mas, muitas vezes estes fatores não são valorizados na sala de aula de forma prática.

Quando questionados se costumam ler para ter prazer, 13 professores mencionaram que apenas às vezes lêem para ter prazer, dando a entender que quando eles podem escolher como passar 0 seu tempo, a leitura não é uma das atividades de lazer preferida. Mais uma vez, observou-se uma relação-afetiva não favorável com a prática de leitura. Ao desejar formar bons leitores é necessário gostar de ler e realizar leituras prazerosas. Tais dados mostram que, é fundamental que os professores e demais mediadores de leitura modifiquem a sua postura em relação à leitura, primeiramente, sejam bons leitores e desenvolvam a "paixão" pelos livros ${ }^{5,8-10}$, para entusiasmar as crianças e não transformar $o$ ato de ler num fim por si mesmo. A leitura é um processo interativo e interdependente, que se desenvolve numa relação de entender o mundo e buscar significados com as suas experiências pessoais, culturais e sociais ${ }^{5}$. 
Outra informação importante é que, na questão que investiga o que você gosta de ler, a leitura técnica, representada por livro da profissão, foi selecionada por alguns professores pesquisados. Tal informação já foi referida em outras pesquisas ${ }^{8,10}$. Assim, é necessário que o professor desenvolva leituras específicas para, estar bem informado, refletir sobre a sua prática pedagógica e contribuir para fazer do Brasil um País de bons leitores ${ }^{5,8}$.

Em consenso, quando questionados sobre o que o hábito de leitura exige, 29 professores selecionaram a opção disposição e interesse pessoal, sendo que um selecionou a opção competências específicas. É certo assegurar que nenhuma leitura é possível sem o adequado funcionamento das habilidades sensoriais e funções corticais superiores. Igualmente, que a leitura exige um saber mínimo para progredir. O hábito de leitura exige desde cedo contato com o livro. Ele pode ser tocado, dobrado, carregado e lido de diversas maneiras: pelas gravuras, imagens, personagens, título, formato, entre outros, de acordo com vários estudos ${ }^{3-8}$. Também, existe várias maneiras de se ler, cabe aos pais, professores ou terapeutas oportunizar circunstâncias reais de leitura, em diferentes situações sociais, que mostrem o sentido da leitura, considerando os aspectos sociais e a história de cada um ${ }^{5-7}$.

Quando indagados sobre como classifica o seu interesse pela leitura, atualmente, 10 professores afirmaram ser regular ou pouco, também, houve nesta questão, associação significante do grupo $(p=0,006)$, sendo que o grupo 3 (pouco favorável) estava mais associado à categoria "regular ou pouco" e o grupo 2 (favorável) teve uma maior proporção de respostas na categoria "ótimo", revelando mais uma vez uma relação afetiva não favorável com a leitura. Em concordância com outros autores ${ }^{8-10}$ é indispensável a presença de professores leitores, que sintam encanto pela leitura, prazer e gosto em aprimorar a sua prática de ensino-aprendizagem da leitura na sala de aula.

Na questão que investiga o que é ler, só 1 professor descreveu a visão afetiva, prazer em ler, quase à metade dos professores delinearam uma visão acadêmica ou lingüística, dado este observado em outras pesquisas ${ }^{8,10}$. Analisando que, ler e escrever não é somente decodificar e codificar grupos de grafemas/fonemas, pois, vai além, envolve a compreensão e reflexão do que foi lido na prática social. Consiste em dominar a leitura e praticá-la no dia-a-dia da vida, ao ler as regras de um jogo, uma receita culinária, uma bula de remédio, um endereço comercial, um contrato imobiliário, uma conta de telefone, um texto e um formulário de modo autônomo ${ }^{5}$. Todavia, o processo de decodificação é essencial para o aprendizado da leitura. Sendo a consciência fonológica uma habilidade possível de ser desenvolvida por meio de atividades lúdicas, especialmente, para as crianças que assinalam dificuldades para aprendizado da leitura ou de risco ${ }^{3,5,12}$. Estudo longitudinal ${ }^{13}$ examinou as contribuições do desenvolvimento da capacidade fonológica e as habilidades orais da língua, no transcorrer do jardim de infância, para o desempenho da leitura em crianças com idade média de 7 anos e 9 meses, cursando a $2^{\text {a }}$ série do ensino fundamental. $70 \%$ dos leitores não-bons apresentaram uma história de problemas em atividades fônicas e em linguagem oral no jardim de infância, concluindo a importância da inclusão de atividades lúdicas para desenvolver consciência fonológica, desde o jardim de infância, para o futuro aprendizado da leitura. Concordando, mais um estudo ${ }^{14}$ destaca que, além do desenvolvimento metafonológico, para o sucesso do aprendizado da leitura, é fundamental oportunizar uma prática extensiva com a própria leitura. Outros estudos ${ }^{3,15}$, também, demonstram que no aprendizado da leitura a criança deve ser conduzida a desenvolver a consciência ortográfica e fonológica, através da análise de forma consciente da linguagem oral, manipulando a palavra, sílaba e fonema durante a própria leitura de histórias.

Quando questionados sobre o que significa ser um bom leitor, apenas seis professores mencionaram uma atitude afetiva com relação à leitura, citando as palavras: gostar, sentir prazer, ter hábito constante de ler vários textos. De acordo com os alguns autores ${ }^{5,10}$ a atitude afetiva na leitura, envolve a ação das emoções: gosto, prazer, encantamento, sensibilidade, interesse, que estabelecem o costume de ler diversos tipos de textos, independente do pouco tempo disponível, pois, o tempo para ler sempre existe para um bom leitor.

$\mathrm{Na}$ questão que investiga com que freqüência realiza a leitura de histórias infantis na sala de aula, metade dos professores afirmou que não tem hábito de realizar a leitura de histórias infantis na sala de aula para seus alunos. Percebe-se, então, que eles, também, desconhecem a relevância da leitura e da literatura infantil na sala de aula, para ajudar a criança a descobrir o prazer da leitura e o gosto pela leitura. A prática de leitura de histórias infantis, como atividade recreativa ou lúdica, é uma experiência agradável, valiosa e significativa que desperta o encanto, à vontade e a disposição para o aprendizado da leitura e da escrita. Vários estudos ${ }^{3-7,12}$ relacionados com o aprendizado da leitura evidenciam a importância de reservar espaços para os programas interativos de leitura e literatura infantil no ambiente escolar, pois, a leitura de histórias infantis promove o desenvolvimento da linguagem oral, do vocabulário, da memória, da compreensão, 
da consciência fonológica, tão importante, para o aprendizado da leitura e da escrita. Sabe-se que, as crianças cometem menos erros na leitura em voz alta, compreendem melhor texto lido em silêncio e empregam uma linguagem mais elaborada para recontar histórias.

No entanto, quando questionados, com base no estudo ${ }^{6}$, qual abordagem de leitura utilizada em sala de aula, mais da metade dos professores responderam a abordagem orientada para o desempenho, onde no momento da leitura, sem o compromisso de avaliar as crianças, o professor encoraja as mesmas a fazerem previsões sobre o que vai acontecer na história, a estabelecerem ligações entre os acontecimentos do texto com suas experiências pessoais, além de acrescentar informações importantes para compreensão da história.

\section{CONCLUSÃO}

Verificou-se que, 30\% dos professores apresentaram um comportamento altamente favorável ou favorável para a leitura (grupo 1 e 2 ) e $70 \%$ dos professores apresentaram comportamento pouco favorável para a leitura (grupo 3). A grande maioria dos professores não desenvolveu uma relação afetiva com o ato de ler e não apresenta hábito de leitura, tão necessário, para formar pequenos leitores em bons leitores e, ainda, desconhecem os propósitos da prática de leitura na sala de aula. É de extrema importância que se realizem projetos de formação para a prática de leitura do professor, onde se discutam as suas atitudes afetivas, experiências pessoais e pedagógicas, as concepções que ele tem sobre a leitura, suas funções e usos, a motivação do aluno para a aprendizagem da leitura e a formação de bons leitores, entre outros.

\begin{abstract}
Purpose: to investigate the professors' behavior and habits from levels 1 to 4 of basic education before the reading and the practical of reading in classroom. Methods: observational, transversal study, with the participation of 30 professors from the levels 1 to 4 , in basic education, from public schools. Through a questionnaire with 15 open and closed questions type, information on the habits and attitudes of the professors had been harvested front to the learning of reading. Results: from this sample of 30 studied teachers, a statically significant difference of behaviors $(p<0.001)$ was found, and this means that a favorable behavior respect to affective relations with reading in childhood, was not prevalent among the teachers. Conclusion: the great majority of teachers did not develop an affective relation with reading, an important requirement to transform learning children in effective and avid young and adult readers.
\end{abstract}

KEYWORDS: Communication; Learning; Education

\section{REFERÊNCIAS}

1. Zorzi JL. Possibilidades de trabalho do fonoaudiólogo no âmbito escolar-educacional. J Cons Fed Fonoaudiol. 1999; 2:14-7.

2. Soares M. Novas práticas de leitura e escrita: letramento na cibercultura. Rev Educ Soc. 2002; 23(81):143-60.

3. Justice LM, Chow SM, Capellini C, Flanigan $\mathrm{K}$, Colton S. Emergent literacy intervention for vulnerable preschoolers: relative effects of two approaches. Am J Speech Lang Pathol. 2003; 12(3):320-32.

4. Gomes MLM. Da materialidade do texto à constituição do leitor: a prática interacionista da leitura como ponto de partida para a instigação sócio-cognitiva. Rev Vértices. 2003; 5(3):81-8.
5. Zorzi JL. O que devemos saber a respeito da linguagem escrita e seus distúrbios: indo além da clínica. In: Andrade CRF, Marcondes E, organizador. Fonoaudiologia em pediatria. vol 1. São Paulo: Sarvier; 2003. p. 120-32.

6. Fontes MJO, Cardoso-Martins C. Efeitos da leitura de histórias no desenvolvimento da linguagem de crianças de nível sócio-econômico baixo. Rev Psic Reflex Crít. 2004; 17(1):83-94.

7. Simões VLB. Histórias infantis e aquisição de escrita. Perspec. 2000; 14(1):22-8.

8. Zorzi JL, Serapompa MT, Oliveira PS, Faria AT. Aspectos da formação de leitores nas quatro séries iniciais do primeiro grau. Rev Ass Bras Psicop. 2003; 20(62):189-201. 
9. Zorzi JL. A influência do perfil de leitor nas habilidades ortográficas. Rev Ass Bras Psicop. 2004; 21(65):146-56.

10. Ferreira SPA, Dias MGBB. A escola e o ensino da leitura. Rev Psic Estud. 2002; 7(1):39-49.

11. Torppa M, Tolvanen A, Poikkeus AM, Eklund $\mathrm{K}$, Lerkkanen MK, Leskinen E, Lyytinen H. Reading development subtypes and their early characteristics. Ann Dyslexia. 2007; 57(1):3-32.
12. Vieira RMR, Grosso PMP, Zorzi JL, Chiappetta ALML. Estudos comparativos sobre a influência da leitura nos erros da escrita entre meninos e meninas de quarta série. Rev CEFAC. 2006; 8(2):281-8.

13. Catts HW, Fey ME, Zhang X, Tomblin JB. Language basis of reading and reading disabilities: evidence from a longitudinal investigation. Scient Stud Read. 1999; 3:331-61.

14. Gough PB. How children learn to read and why they fail. Ann Dyslex. 1996; 46(1):1-20.

RECEBIDO EM: 03/07/2007

ACEITO EM: 13/02/2008

Endereço para correspondência:

Rua Passo Real, 61

Salto do Jacuí - RS

CEP: $99440-000$

Tel: (55) 3327-2385

E-mail: tristananb@gmail.com 